\title{
Increasing the Energy-Efficiency of Induction Machines by the use of Grain Oriented Magnetic Materials and Die Casting Copper Squirrel Cage in the Rotor
}

\author{
Vincent Mallard ${ }^{1,2}$, Guillaume Parent ${ }^{1}$, Cristian Demian ${ }^{1}$, Jean-François Brudny ${ }^{1}$, Aurélien Delamotte ${ }^{2}$ \\ ${ }^{1}$ Univ. Artois, EA 4025, Laboratoire Systèmes Électrotechniques et Environnement (LSEE), F-62400 Béthune \\ ${ }^{2}$ FAVI SA, F-80490 Hallencourt
}

\begin{abstract}
This paper deals with an induction machine whose squirrel cage is made of copper obtained by die casting process. The major issue of this process is the thermal shock suffered by the laminations, leading to the deterioration of insulation coating as well as the generation of interbar currents, those currents being responsible for addition stray losses. This issue can be counteracted by using grain oriented laminations on the rotor. In particular, the paper highlights that due to the specificity of the insulation coating of that kind of electrical steel it does not suffer from the thermal shock. It is shown that using a squirrel cage made of copper combined to grain oriented laminations in the rotor leads to a decrease of both core losses and stray load losses and an increase of the efficiency of $1.6 \%$.
\end{abstract}

Keywords - die casting copper, core losses, grain oriented electrical steel, stray load losses, induction machine.

\section{INTRODUCTION}

Nowadays, increasing the efficiency of electrical motors has become a priority in order to reduce electricity consumption and $\mathrm{CO}_{2}$ emissions. This is why an International Standard [1], dated 2014, specifies an efficiency class for electrical motors. A lot of studies on the subject can be found in the literature. The most common technique used by machine manufacturers is the core-stack length approach $[2,3]$ which simply consists in increasing the stack length. However this concept is limited, particularly when the machines are already IE3 or IE4 [4].

Another approach consists in replacing aluminium by copper in the squirrel cage [5]-[8] in order to take advantage of the latter lower electrical resistivity. It is shown in the literature that using that king of squirrel cage can significantly reduce rotor Joule losses. As an example, an efficiency increase of $2 \%$ can be obtained with $1.5 \mathrm{~kW}, 3 \mathrm{~kW}$ and $7.5 \mathrm{~kW}$ motors without modifying their size [8]. Of course, it is also possible to reduce the motor size while keeping the same performance. The main difficulty with that technique is about the tool lifetime since the high melting point of pure copper may result in fast deterioration of the foundry tooling. Nevertheless, this drawback can be solved by choosing the proper material for those tools [9], making it possible to get a commercially feasible process [10]. Another issue encountered with squirrel cage obtained by high pressure die casting, whether made of aluminium or copper,

Corresponding author: G. Parent (email: guillaume.parent@univ-artois.fr) is the deterioration of slot insulation during the manufacture. This phenomenon is responsible for interbar currents occuring in the rotor [11] leading to additional stray losses [12].

Another method for increasing the efficiency of an electrical device is to consider the best electrical steel possible in terms of magnetic performance. Due to its isotropic properties, Non Oriented (NO) steel is best suited for the design of devices under rotational magnetic field conditions, which is why the very large majority of rotating electrical machines are built with this material. On the other hand, Grain Oriented (GO) electrical steel presents very good magnetic performances, i.e. way lower core losses and higher magnetic flux density at saturation, compared to NO in the Rolling Direction (RD). Its high anisotropic behavior is the reason why it is very best suited for unidirectional electric excitation whereas it is not widespread in rotating machines. For that kind of application it is encountered in the form of segmented laminations in permanent magnet synchronous machines [13] and switched reluctance machines [14]. It is also encountered in the form of non-segmented shifted stack in induction machines [15]-[17]. In this case, the gain of efficiency is around $2 \%$ [18]. GO electrical steel also presents a better electrical insulation than NO material since the insulation coating is created during the manufacturing process [19]. This can be a solution to counteract the aforementioned interbar currents.

Works presented in this paper deal with the study of an induction machine composed of a copper squirrel cage realized by high pressure die casting copper and a rotor core made of GO electrical steel sheet in order to decrease the core losses and the stray load losses. In the first part, the die casting process is described in order to explain the reason why the insulation coating and the thermal shock have an impact on the efficiency of the machine. In order to validate the use of GO electrical steel associated to die casting copper process, several samples are annealed at different temperatures. A comparison with and without annealing in terms of magnetization curve and core losses is presented. In the second part, the new assembly method of magnetic circuit with GO electrical steel is explained. In order to validate the use of GO in AC machines, a simple experimental structure allowing to compare cores made of different electrical steel sheet grade and thickness is presented. In the third part, a comparison between a die 
casting copper rotor with NO material and a die casting rotor with GO material is shown. The last part is a discussion in which the authors explain the gain of die casting copper rotor with GO electrical steel in terms of core losses in the induction machine.

\section{DIE CAST SQUIRREL CAGE}

\section{A. Influence of die casting process on NO electrical steel}

Usually, the squirrel cage of an induction machine is made of high pressure die casting aluminium, which is widely recognised as an affordable manufacturing process. During the process, the rotor core plays the role of mold in which molten aluminium is poured. In consequence, the electrical steel sheets composing the rotor are subject to a thermal shock [20] but the melting temperature of aluminium $\left(600^{\circ} \mathrm{C}\right)$ is low enough so that they are not damaged during the process. The melting temperature of copper being way higher $\left(1083^{\circ} \mathrm{C}\right)$, building a squirrel cage cast in copper implies the process to be performed at a temperature between $1100^{\circ} \mathrm{C}$ and $1200^{\circ} \mathrm{C}$. Hence, the electrical steel sheets are subject to a way more important and faster thermal shock [21]-[24] whose effects can differ according to their grade [25]-[30]. On one hand, a deterioration in terms of core losses was observed for the fully processed electrical steel for an annealing temperature above $700{ }^{\circ} \mathrm{C}$. On the other hand, an improvement of magnetic properties is noted for the semi processed steel for a temperature above $1000^{\circ} \mathrm{C}$. Moreover, no matter the grade, the thermal shock often leads to a shorting of the electrical steel sheets on the contact are with bar conductors as shown in Fig. 1. This shorting is responsible for the deterioration of interbar resistance, leading to the apparition of interbar currents, which is observed on machines with squirrel cage made of die casting copper [11,31].

\section{B. Using GO material with die casting copper process}

Usually, the cores of AC electrical motors are laminated in order to reduce the effects of eddy currents and to minimize core losses. Most of motors manufacturers use NO fully processed electrical steels with standard organic or inorganic coatings. Die casters recommend the latters to be of Class 5 , that is their maximum annealing temperature is $850^{\circ} \mathrm{C}$, which suits well with the aluminium squirrel die casting process but is not enough to deal with copper. This is where it is possible to take advantage of GO electrical steel coating good properties. It is divided in two different parts. The first part - the glass film - is produced by high temperature annealing around $1200^{\circ} \mathrm{C}$ during the decarburization process. The second part is a phosphate coating deposited on steel

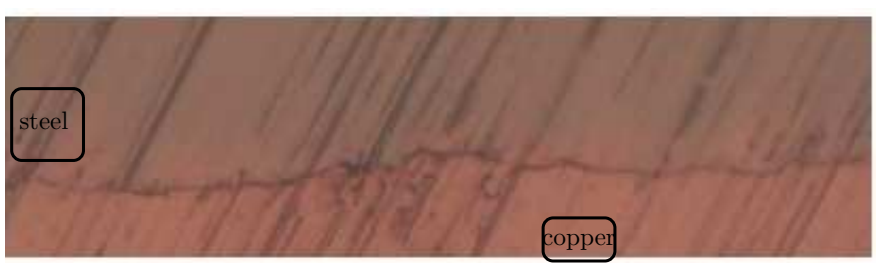

Fig. 1. Zoom on contact part in order to create an elastic tensile stress and to decrease the core losses. Obviously, the main interest of GO electrical steel for die cast copper is the first part of insulation coating because of its high temperature resistance property [32]. In order to validate the possibility of using GO electrical steel with die casting copper process, heating tests are realized on standardized samples [33]. Moreover, in order for thoses tests to be representative of die casting process, three temperatures are considered: $1100^{\circ} \mathrm{C}, 950^{\circ} \mathrm{C}$ and $650^{\circ} \mathrm{C}$. The first temperature, $1100^{\circ} \mathrm{C}$, corresponds to the temperature of contact between copper and rotor laminations. The second temperature, $950^{\circ} \mathrm{C}$, is an intermediate temperature reached by the electrical steel during the process. The last temperature tested, $650{ }^{\circ} \mathrm{C}$, is a maximum temperature reached in the middle of a rotor teeth. Moreover, the cooling mode is the natural cooling of the furnace which corresponds to the one involved during the die casting copper process. The annealing cycles are presented in Figs. 2a, 2b and 2c. The impact of those thermal cycles on $\hat{b}(\hat{h})$ curves and core losses are presented in Figs. 3 and 4 respectively. Both figures clearely show that neither $\hat{b}(\hat{h})$ curves nor core losses are affected by the thermal shock which implies that GO electrical steel can be used to make a rotor with die casting copper squirrel cage.

\section{USING GO SHEETS IN AC MACHINES}

GO electrical steel presents a very highly anisotropic behavior. In particular, $\hat{b}(\hat{h})$ curves and core losses greatly depend on the angle, noted $\alpha$, between the magnetic field direction and the sheet RD. As an illustration, figs. 5 and 6 present $\hat{b}(\hat{h})$ curves and core losses for HGO35 steel and for several values of $\alpha$. For comparison, those figures also show those properties for NO50 and NO35 steel, which are the most commonly used in rotating machines. This highly anisotropic behavior is the reason why GO electrical steel is usually used for transformers and high power rotating machines with segmented sheets in order to take advantage of RD good magnetic properties. In the case of small machines, that is machines for which segmented sheets is not an option, it appears that building the magnetic core by shifting each sheet to the other by a $\beta$ angle referring to the RD (Fig. 7) is an interesting option. That way, depending on the location in the stack, the magnetic flux can take advantage of each sheet RD [34]. A previous work [18] showed that the optimal value of $\beta$ in terms of energy efficiency is found at $90^{\circ}$.

\section{A. Static Machine}

To determine the advantage of our assembly method in terms of core losses, experiments are performed on static machines whose behavior is similar to transformers under rotating field conditions, but correspond to a four-pole induction machine design without rotor slots (Fig. 8). They are designed such that their cores require few magnetic field to be saturated. Note that the uniformity of the airgap thickness is ensured by using three small joints that fasten the rotor to the stator (Fig. 8). As for the electrical circuit, it is composed of two four-pole three-phase star-connected windings. The first one, composed of five turns, is used to supply the machine 


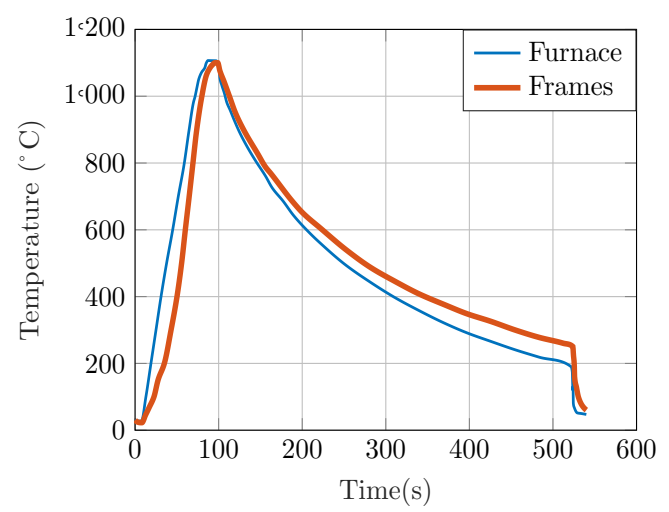

(a) Annealing cycle at $1100^{\circ} \mathrm{C}$

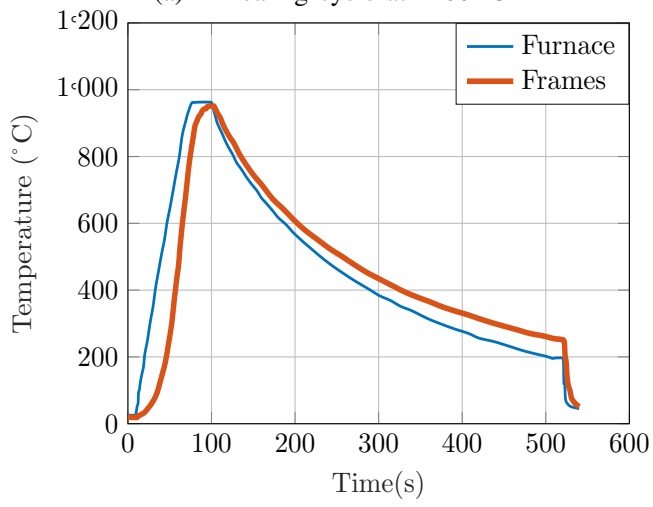

(b) Annealing cycle at $950^{\circ} \mathrm{C}$

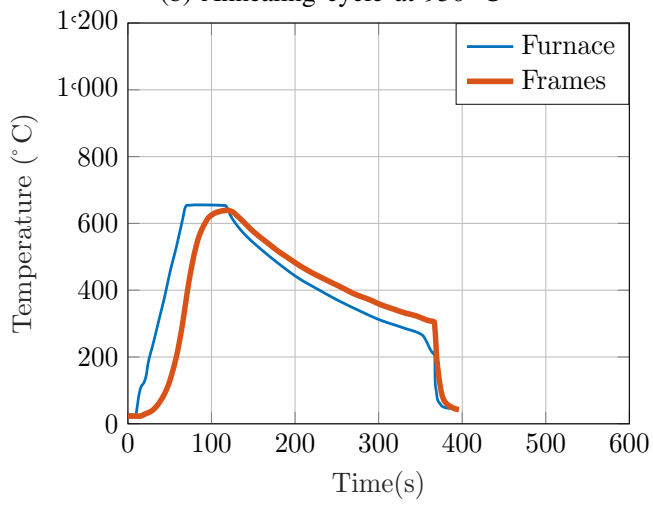

(c) Annealing cycle at $650^{\circ} \mathrm{C}$

Fig. 2. Annealing cycle on Epstein Frame

whereas the second one, composed of one turn, is devoted to the electromotive force measurement. Such a device allows to test different magnetic circuit assembly configurations, which would hardly be possible with actual induction machines due to construction time and cost.

\section{B. Core losses measurement}

As stated in section III-A, the static machine rotor can not enter into rotation, contrary to an actual induction machine. Two conclusions can be deduced from that: static machines can be considered as transformers and their rotor and stator magnetic fluxes share the same frequency. This is why the equivalent single-phase scheme presented in Fig. 9 can be used for its modeling, where $R_{\mathrm{p}}$ represents the primary winding copper losses, $X_{\mathrm{p}}$ is the primary winding leakage inductance, $X_{\mu}$ allows to characterize the reactive power required to

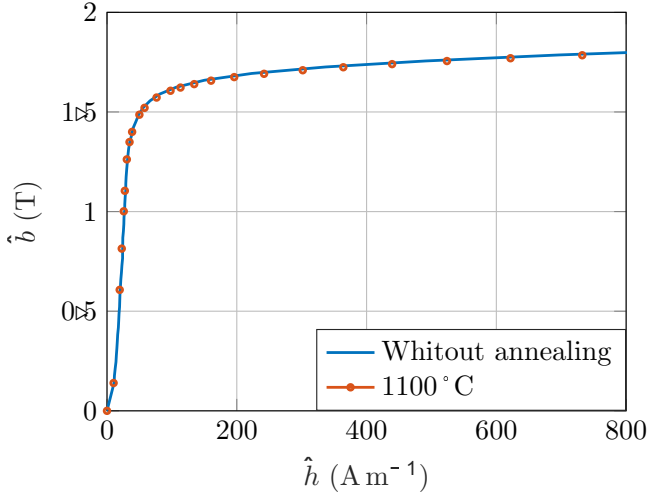

(a) $\hat{b}(\hat{h})$ curves with or without annealing at $1100^{\circ} \mathrm{C}$

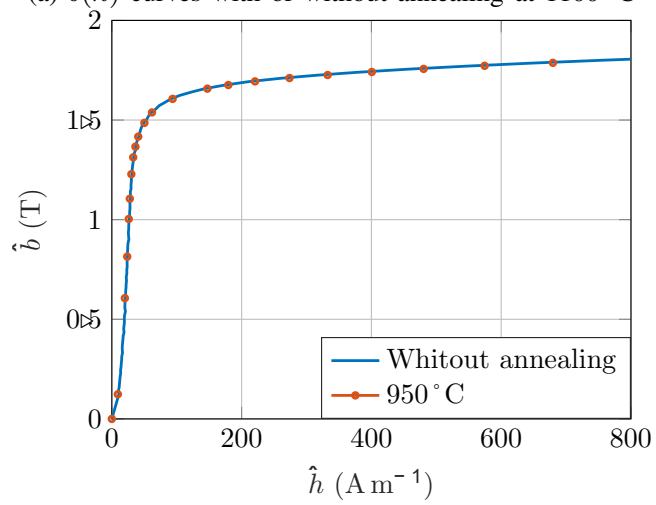

(b) $\hat{b}(\hat{h})$ curves with or without annealing at $950^{\circ} \mathrm{C}$

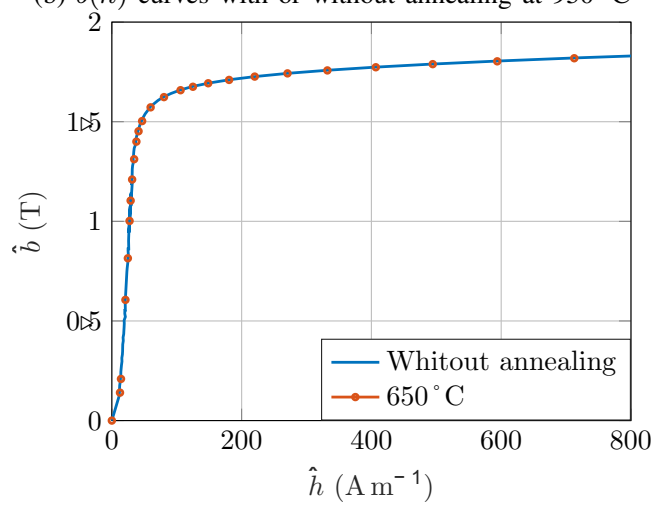

(c) $\hat{b}(\hat{h})$ curves with or without annealing at $650{ }^{\circ} \mathrm{C}$

Fig. 3. $\hat{b}(\hat{h})$ curves with and without annealing

magnetize the machine and $R_{\mu}$ is tied to the rotor and stator core losses. $R_{\mathrm{s}}$ and $X_{\mathrm{s}}$ represent the secondary Joule losses and the flux leakage inductance respectively. As for the electrical variables, $\underline{V}_{\mathrm{p}}$ is the primary voltage, $\underline{I}_{\mathrm{p}}$ is the primary current, $\underline{E}_{\mathrm{p}}$ represents the electromotive force seen from the primary side, $\underline{E}_{\mathrm{s}}$ represents the electromotive force seen from the secondary side and $\underline{V}_{\mathrm{S}}$ is the secondary voltage. The last parameters $m$ is the turn ratio.

\section{Measurements}

In order to determine $R_{\mu}$, a sinusoidal voltage $\underline{V}_{\mathrm{p}}$ is applied to the primary winding. A Yokogawa WT3000 digital power meter is used to measure the stator current $\underline{I}_{\mathrm{p}}$ and the secondary voltage $\underline{V}_{s}$. As $I_{\mathrm{s}}=0$ then $\underline{V}_{\mathrm{s}}=\underline{E}_{\mathrm{s}}$. Since the primary and secondary windings are implemented in two identical sec- 


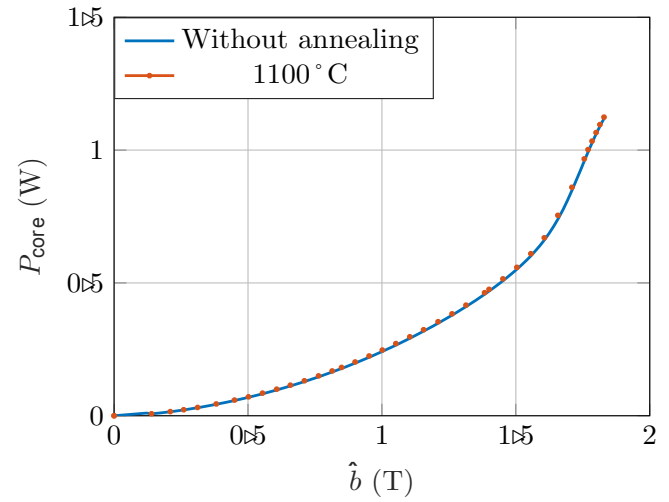

(a) $P_{\text {core }}(\hat{b})$ curves with or without annealing at $1100{ }^{\circ} \mathrm{C}$

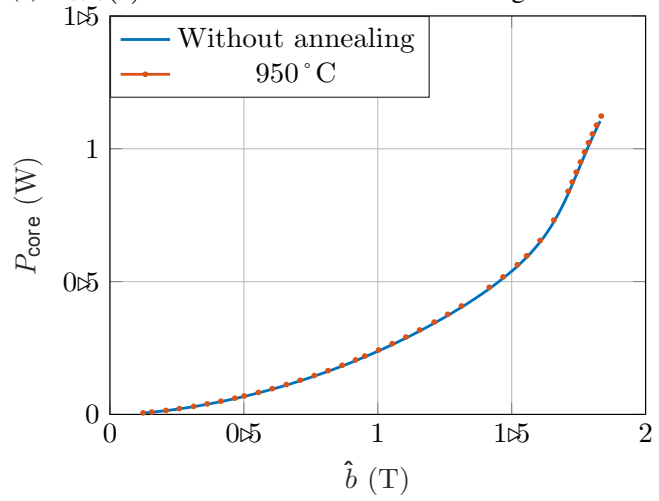

(b) $P_{\text {core }}(\hat{b})$ curves with or without annealing at $950^{\circ} \mathrm{C}$

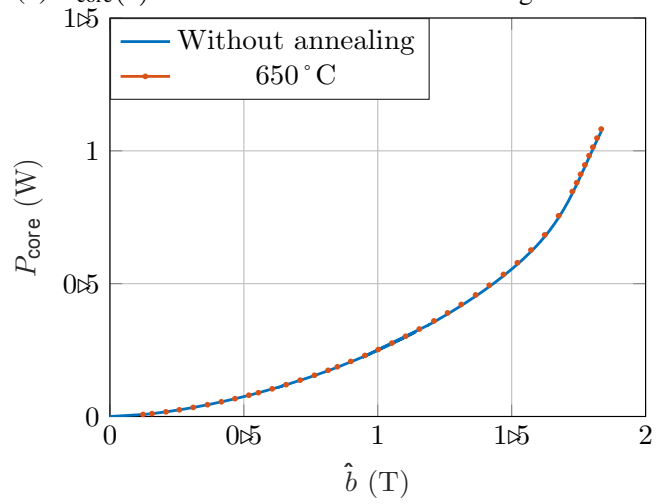

(c) $P_{\text {core }}(\hat{b})$ curves with or without annealing at $650^{\circ} \mathrm{C}$

Fig. 4. $P_{\text {core }}(\hat{b})$ curves with and without annealing

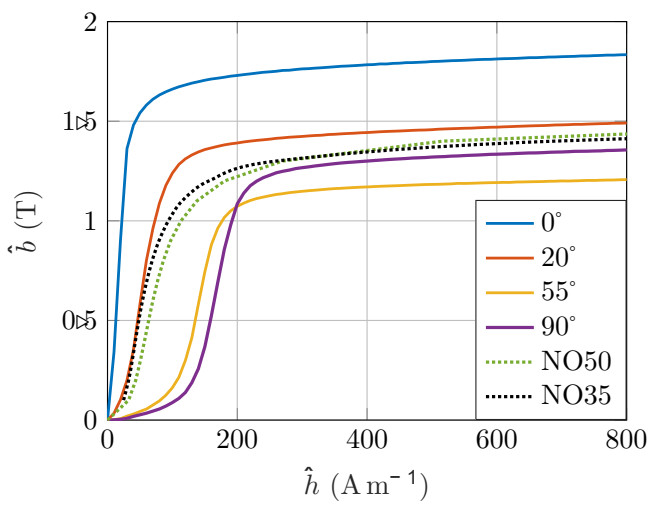

Fig. 5. $\hat{b}(\hat{h})$ curves for different materials and different angle $\alpha$

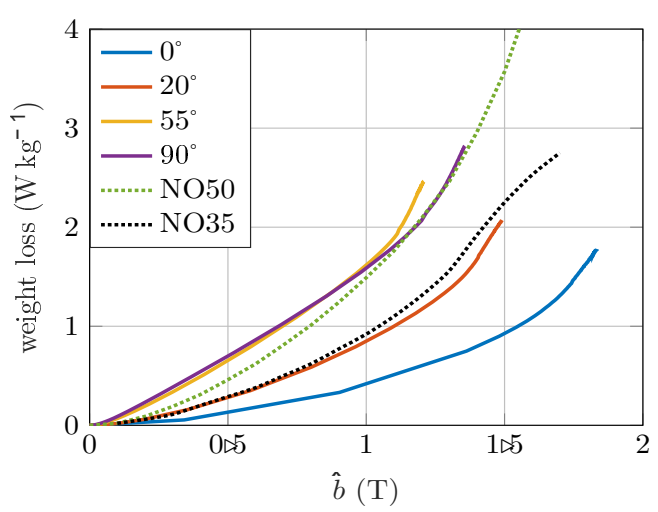

Fig. 6. Core losses for each $\hat{b}(\hat{h})$ curve

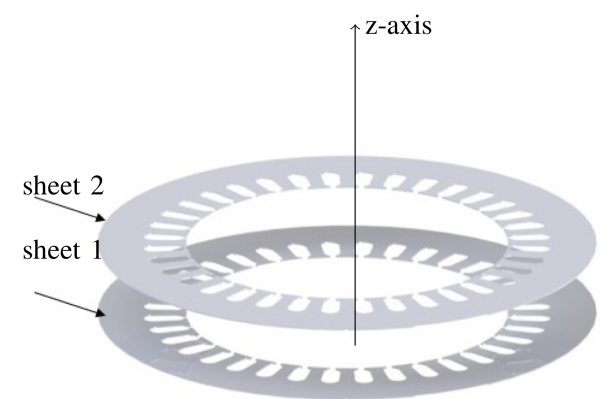

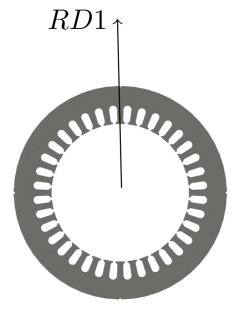

sheet 1

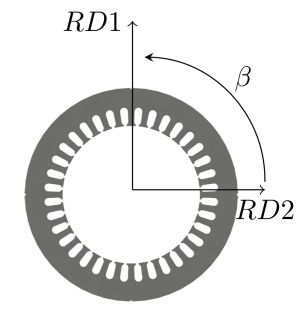

sheet 2
Fig. 7. GO assembly method
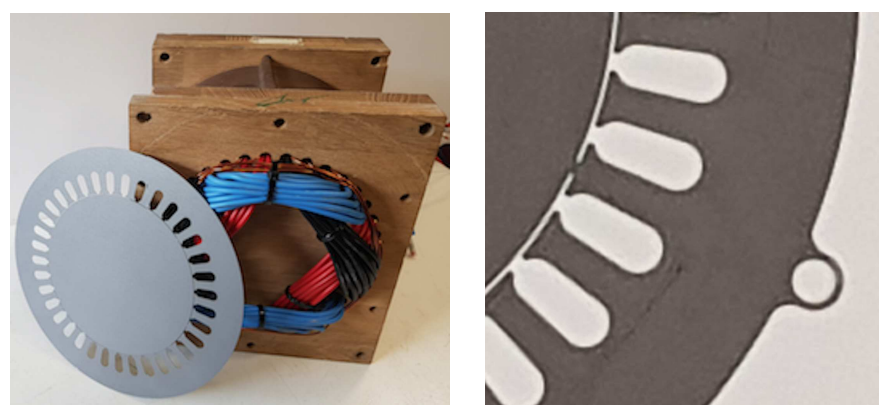

Fig. 8. Static machine (left) - zoom on the air gap (right)

tions with a different number of turns, the electromotive force in the primary winding can be expressed by (1). Therefore, the core losses can be expressed by (2), where $\varphi$ is the phase shift between $\underline{I}_{\mathrm{p}}$ and $\underline{E}_{\mathrm{s}}$. Hence, $R_{\mu}$ can be defined by (3). The main advantage of this measurement procedure is that it makes it possible to circumvent the difficulty posed by the voltage drops in $R_{\mathrm{p}}$ and $X_{\mathrm{p}}$.

$$
E_{\mathrm{p}}=\frac{E_{\mathrm{s}}}{m}
$$




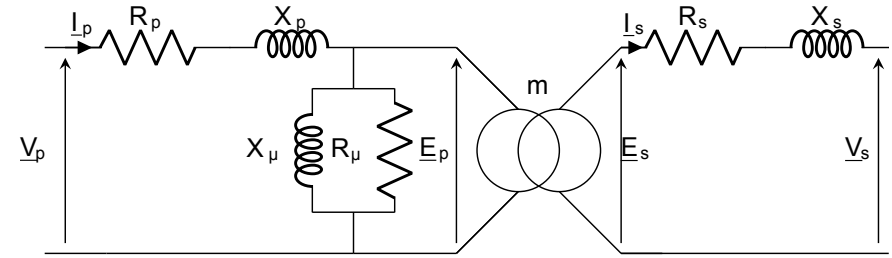

Fig. 9. Equivalent single-phase scheme

TABLE I

STATIC MACHINE CONFIGURATIONS

\begin{tabular}{lll}
\hline \hline Configurations & Materials & Denomination \\
\hline 1 & M400-50A & NO50 \\
2 & M235-35A & NO35 \\
3 & M145-35S & CGO35 \\
4 & M125-35P & HGO35 \\
\hline \hline
\end{tabular}

$$
\begin{gathered}
P_{\text {core }}=3 m E_{\mathrm{s}} I_{\mathrm{p}} \cos \varphi \\
R_{\mu}=\frac{3 E_{\mathrm{p}}^{2}}{P_{\text {core }}}
\end{gathered}
$$

The air-gap magnetic flux density $\hat{b}_{\mathrm{ag}}$ is a key parameter in an electrical machine design. That is why the results are expressed at different levels of $\hat{b}_{\mathrm{ag}}$. It can be expressed by (4) where $n_{\mathrm{a}}$ represents the number of turn of the secondary winding, $k_{\mathrm{a}}$ is the winding coefficient of the secondary winding, $r$ is the stator inner radius, $l$ is the iron active length and $\omega$ is the electrical pulsation.

$$
\hat{b}_{\mathrm{ag}}=\frac{\sqrt{2} E_{\mathrm{s}}}{2 n_{\mathrm{a}} k_{\mathrm{a}} r l \omega}
$$

\section{Results}

The different grades used to make these static machines are presented in Table I. Two kinds of GO materials, conventional (CGO35) and high permeability (HGO35), are used. The variations of $P_{\text {core }}$ with $\hat{b}_{\mathrm{ag}}$ are shown in Fig. 10 with $n_{\mathrm{a}}=3$, $k_{\mathrm{a}}=0.96, r=59.5 \mathrm{~mm}, l=8 \mathrm{~cm}$ and $\omega=100 \pi$.

It can be noted that HGO material is known to present a higher deterioration of its magnetic properties along other directions than RD [35] compared to CGO. Nevertheless, the best configuration is obtained for the static machine made of HGO35 which brings large reduction of stator and rotor core losses. In the range from $0 \mathrm{~T}$ to $0.7 \mathrm{~T}$, this difference is mainly due to the magnetic properties from the linear part of the $\hat{b}(\hat{h})$ curve. Nevertheless, when $\hat{b_{\mathrm{ag}}}$ exceeds $0.7 \mathrm{~T}$, the gain becomes modest in comparison to NO35 because the RD becomes saturated. It means that the magnetic flux tends to establish in other directions. Despite this drawback, the static machine made of $\mathrm{HGO} 35$ presents less core losses compared to the other configurations.

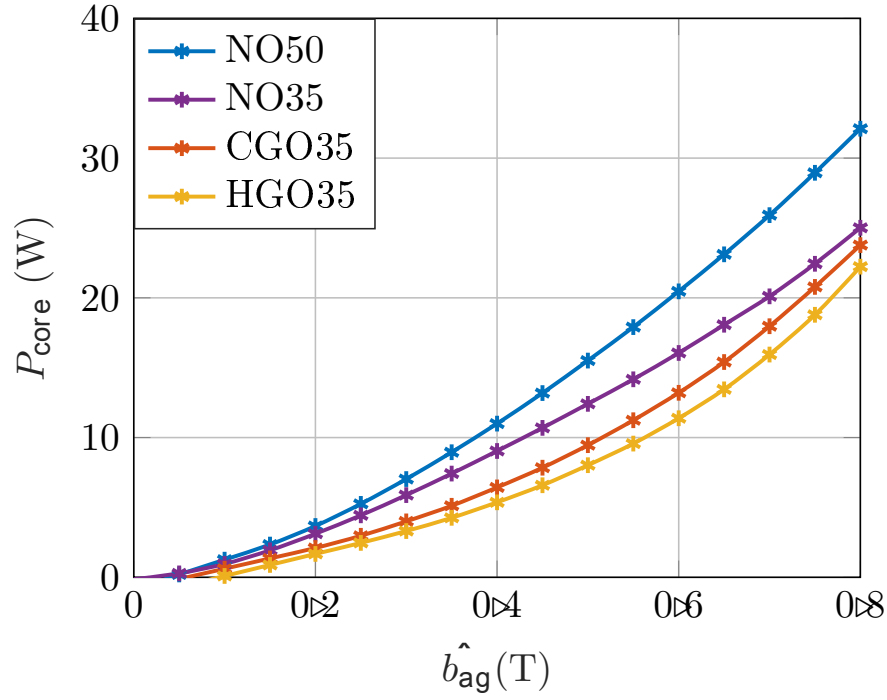

Fig. 10. $P_{\text {core }}$ at different $\hat{b_{\mathrm{ag}}}$ levels.

\section{INDUCTION MACHINE WITH GO MAGNETIC MATERIALS AND DIE CASTING COPPER SQUIRREL CAGE}

\section{A. Test bench and tested machines}

The test bench is presented in Fig. 11. It is composed of the tested machine, a dynamometer that allows to measure the speed as well as the mechanical torque and two thermocouples. The first one allows to measure the stator windings temperature whereas the second one is for the coolant - which is air in our case - temperature. Moreover, a DC machine is mechanically linked to the tested machine in order to allow to create loading conditions. The tested machine is supplied by a purely sinusoidal voltage delivered by an autotransformer. The DC machine is supplied by a pure DC voltage and all the electrical quantities related to the tested machine are measured by a 3-phase wattmeter NORMA D5000.

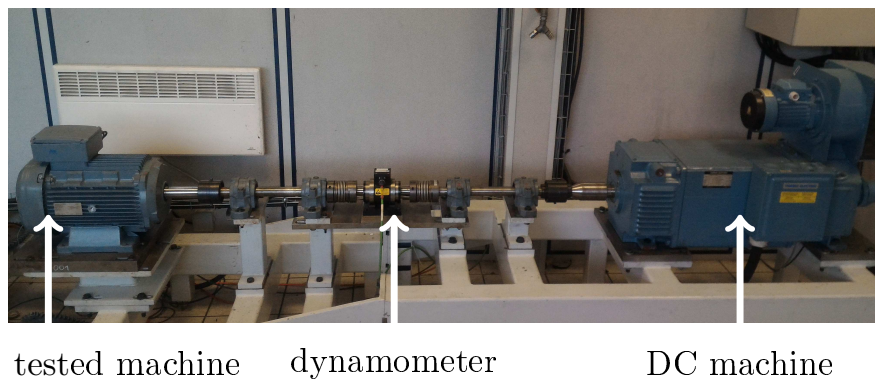

Fig. 11. Test bench

The tested machines come from an $11 \mathrm{~kW}$ four-pole induction machine. The main characteristics are given in Table II. The stator magnetic circuit is made of $0.50 \mathrm{~mm} \mathrm{NO}$ electrical steel sheets (M400-50A). The first tested induction machine, noted M1, corresponds to a machine with a die casting copper rotor made of NO material. The second one, noted M2, only differs from M1 in terms of electrical steels constituting the rotor. M1 and M2 use the same stator in order to keep the same original stator winding resistance and stator magnetic 
TABLE II

MAIN CHARACTERISTICS AND DIMENSIONS OF M1 AND M2

\begin{tabular}{lc}
\hline \hline Rated power $(\mathrm{kW})$ & 11 \\
Voltage supply $(\mathrm{V})$ & $380-420 / 660-720$ \\
Current line (A) & $22 / 12,9$ \\
Power factor & 0,81 \\
Stack length $(\mathrm{mm})$ & 210 \\
Outer stator diameter $(\mathrm{mm})$ & 210 \\
Inner stator diameter $(\mathrm{mm})$ & 134 \\
Outer rotor diameter(mm) & 133,35 \\
Air-gap (mm) & 0,65 \\
Stator slot & 36 \\
Rotor slot & 28 \\
Skew $\left(^{\circ}\right)$ & 10 \\
\hline \hline
\end{tabular}

core. That way, it allows to compare only the initial rotor and the new rotor prototypes.

\section{B. Efficiency Measurement}

The efficiency of electrical motor is defined by:

$$
\begin{gathered}
\eta=\frac{P_{\text {in }}-P_{\text {loss }}}{P_{\text {in }}}=\frac{P_{\text {out }}}{P_{\text {in }}} \\
P_{\text {loss }}=P_{\text {core }}+P_{\mathrm{fw}}+P_{\mathrm{js}}+P_{\mathrm{jr}}+P_{\text {stray }}
\end{gathered}
$$

where $P_{\text {out }}$ is the mechanical power, $P_{\text {in }}$ is the input power, $P_{\text {loss }}$ is the sum of all losses in the motor, $P_{\text {core }}$ includes both stator and rotor core losses, $P_{\mathrm{js}}$ is the stator winding losses, $P_{\mathrm{jr}}$ is the rotor winding losses, $P_{\text {stray }}$ corresponds to stray load losses and $P_{\mathrm{fw}}$ is the friction and windage losses. The mechanical losses and the stator and rotor core losses come from the no-load test at variable voltage levels. The stator winding losses, rotor winding losses and stray load losses come from load tests. In that case, the motor is coupled to a dynamometer. The rotor winding losses are defined by the product of the slip and the electromagnetic power. The stray load loss, as described in [36] can be defined either from test measurements or by assigning a value.

\section{No-load test}

The no-load tests are performed at $50 \mathrm{~Hz}$ and different phase-to-neutral voltage supply values $V$ are considered in order to determine the core losses, the stator winding losses and the mechanical losses. Note that the no-load test is performed right after the load test in such a way both tests are performed at the same temperature. The mechanical losses, which are the sum of the friction losses and the windage losses, are classically determined, according to standard [36], from the extrapolation of the curve $\left(P_{\mathrm{in}}-P_{\mathrm{js}}\right)=f\left(V^{2}\right)$ since they correspond to the Y-intercept, i.e. $f(V=0)$. The active power is presented in Fig. IV-B. It clearly shows that M2 presents a lower power consumption compared to M1. The friction and windage losses are $157.9 \mathrm{~W}$ for M1 and $147.2 \mathrm{~W}$ for M2. This difference of $10.7 \mathrm{~W}$ can be explained by the assembly and dismantling in order to use the same stator. Indeed, even if both shafts and bearings are chosen identical for M1 and M2, a building factor always remains and the characteristics of the bearings can slightly differ.

The active power is presented in Fig. IV-B. The gain on the no-load power is $14.77 \%$ at $220 \mathrm{~V}$. The total core losses are given in Figs. IV-B. The total gain of stator and rotor core losses is $29.77 \%$ at $220 \mathrm{~V}$. This gain is mainly due to the better insulation coating of GO electrical steel which allows to reduce interbar currents and no-load stray losses [37]. Nevertheless, GO electrical steel insulation are not sufficient to explain this improvement. The residual gain is as a result of magnetization current difference $(6.8 \%)$ between M1 and $\mathrm{M} 2$ at $220 \mathrm{~V}$. The fundamental airgap magnetic flux density is $0.803 \mathrm{~T}$ for M1 and $0.797 \mathrm{~T}$ for M2. It can be noted that the slight difference allows to confirm the previous results and to eliminate the interrogation for the airgap thickness.

\section{Stray load loss}

As stated in section IV-B, the stray load losses can be determined with load operations. The mechanical power is measured by a dynamometer as a product of the torque by the speed. The stray load losses are calculated by removing the conventional losses from the apparent total losses. The apparent total losses are defined by:

$$
P_{\text {app }}=P_{\text {in }}-P_{\text {out }}
$$

The residual losses are defined by:

$$
P_{\mathrm{str}}=P_{\mathrm{app}}-\left(P_{\text {core }}+P_{\mathrm{fw}}+P_{\mathrm{js}}+P_{\mathrm{jr}}\right)
$$
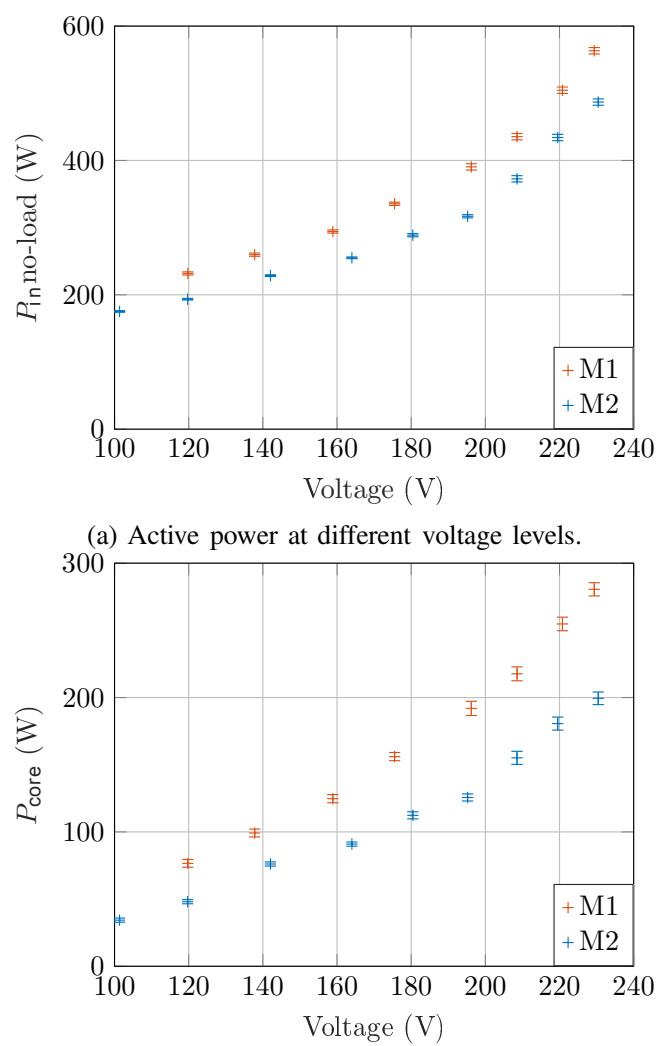

(b) Core losses at different voltage levels.

Fig. 12. Results of no-load test 


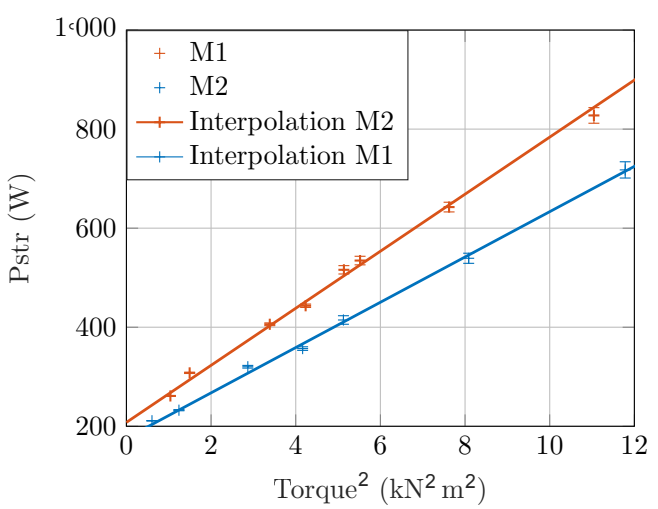

Fig. 13. Stray load losses

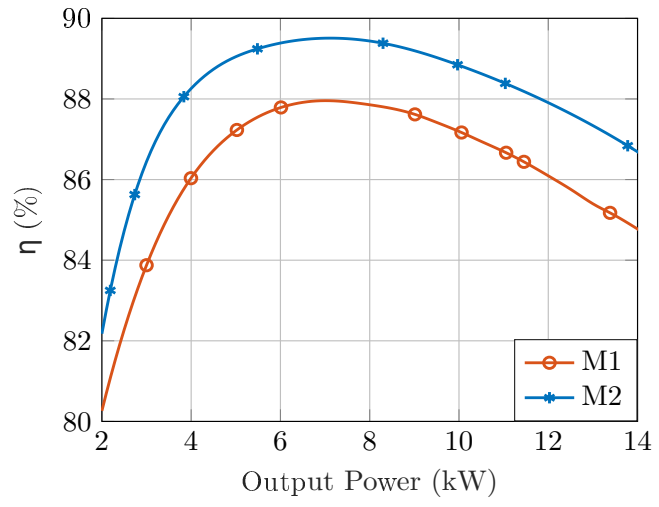

Fig. 14. Efficiency according to IEC60034-2-1

In order to obtain the stray load losses, the residual losses measured are smoothed with a linear regression as shown in Fig. 13. This regression analysis is based on the expression of the losses as a function of square of the load torque and it is defined as follows:

$$
\begin{gathered}
P_{\text {str }}=A T^{2}+B \\
P_{\text {stray }}=A T^{2}
\end{gathered}
$$

where $A$ and $B$ are constant coefficients. The offset $B$ is removed in expression (9) to obtain the corrected stray load losses (10) [36]. The test is considered acceptable if the coefficient of correlation is at least 0.95 according to standard [36]. In our cases, it is equal to 0.9977 for the machine with rotor made of GO material and it is equalt to 0.9952 for the original motor. Coefficient $A$ is equal to 0.0577 for M1 and equal to 0.045 for M2. In order to minimize the measurement errors on this quantity, recommendations presented in [38] have been followed. The stray load losses maximum error measurement is $\pm 3 \%$ for $\mathrm{M} 1$ and $\pm 3.65 \%$ for $\mathrm{M} 2$.

\section{E. Results}

Both configurations are tested according to standard [36]. M1 and M2 are supplied by a sinusoidal voltage source at $50 \mathrm{~Hz}$ and $380 \mathrm{~V}$ phase-to-phase. The efficiency of M1 and M2 at different operation loads is shown in Fig. 14. The difference of all losses is presented in Table III at nominal operation $(11 \mathrm{~kW})$. The gain of efficiency is 1.6 points. It is
TABLE III

LOSSES OF M1 AND M2 AT $11 \mathrm{~kW}$

\begin{tabular}{ccc}
\hline \hline Configurations & M1 & M2 \\
\hline Torque $(\mathrm{Nm})$ & 72.84 & 72.52 \\
Speed (Rpm) & 1471.5 & 1472.1 \\
Slip (\%) & 1.89 & 1.85 \\
$P_{\text {in }}(\mathrm{W})$ & 12917.58 & 12647.35 \\
$V_{\text {in }}(\mathrm{V})$ & 219.35 & 219.65 \\
$I_{\text {in }}(\mathrm{A})$ & 24.093 & 23.892 \\
$P_{\mathrm{js}}(\mathrm{W})$ & 785.96 & 712.07 \\
$P_{\text {core }}(\mathrm{W})$ & 218.58 & 158.019 \\
$P_{\mathrm{fw}}(\mathrm{W})$ & 157.9 & 147.2 \\
$P_{\mathrm{jr}}(\mathrm{W})$ & 225.62 & 219.01 \\
$P_{\text {stray }}(\mathrm{W})$ & 306.16 & 231.99 \\
$\eta(\%)$ & 86.8 & 88.4 \\
\hline \hline
\end{tabular}

obtained by the reduction of all terms of $P_{\text {loss }}$ in (6). The main reduction is, as expected, obtained on core losses $P_{\text {core }}$ around $27 \%$. The reduction on $P_{\text {stray }}$, as for it, is equal to $24.2 \%$ and is due to the better insulation of GO electrical steel and the better behavior of GO electrical steel with die casting copper process.

A consequence of the core losses decrease is that the operating temperature in $\mathrm{M} 2$ is lower that the one in $\mathrm{M} 1\left(89^{\circ} \mathrm{C}\right.$ compared to $118^{\circ} \mathrm{C}$ ). Then, the stator winding resistor is equal to $0.4157 \Omega$ for M2 whereas it is equal to $0.4515 \Omega$ for M1 which also leads to an improvement of $9.4 \%$ in terms of Joule losses.

\section{DISCUSSION}

The rotor core losses in induction machines during a noload test are usually assumed to be insignificant because the speed is very close to the synchronous one. Hence, one might wonder whether it is relevant to use GO sheets in the rotor core. A first answer has already been brought in section II since GO sheets are not impacted by the die casting process. Nevertheless, the aforementioned assumption on rotor core losses seems to be too strong in our case. This issue has already been raised in [39]. In order to highlight this point, we propose the following test: a DC machine mechanically linked to a wound rotor induction machine are considered. The reason why such an induction machine is considered instead of a squirrel cage one is that the rotor windings are perfectly insulated from the rotor laminations and so there is no interbar currents. It allows us to distinguish the stator from the rotor effects included in $P_{\text {core }}$. The DC machine is used as a motor to drive the induction machine at its synchronous speed. The induction machine stator windings are supplied by a balanced sinusoidal three phase voltage at $50 \mathrm{~Hz}$. The balance of power of this test bench is presented in Fig. 15, where $P_{\text {in }} \mathrm{AC}$ is the input power of the induction machine and $P_{\mathrm{in}} \mathrm{DC}$ is input power of DC machine. $P_{\mathrm{j}} \mathrm{AC}$ and $P_{\mathrm{j}} \mathrm{DC}$ represent the induction machine stator winding losses and the DC machine winding losses respectively and $P_{\mathrm{fw}}$ represents the mechanical losses of the bench. Note that $P_{\mathrm{fw}}$ includes the core losses of the DC machine since they can be assimilated to a torque loss. 
TABLE IV

COMPARISON WRIM CLASSICAL NO-LOAD TEST VS DCM TEST

\begin{tabular}{ccc}
\hline \hline Test & No-load & DCM test \\
\hline$V_{\mathrm{AC}}(\mathrm{V})$ & 224.221 & 222.616 \\
$I_{\mathrm{AC}}(\mathrm{A})$ & 4.215 & 4.079 \\
$P_{\text {in }} \mathrm{AC}(\mathrm{W})$ & 549.291 & 189.59 \\
$P_{\mathrm{j}} \mathrm{AC}(\mathrm{W})$ & 94.31 & 88.34 \\
$P_{\text {in }} \mathrm{DC}(\mathrm{W})$ & - & 350.131 \\
$P_{\mathrm{j}} \mathrm{DC}(\mathrm{W})$ & - & 4.66 \\
$P_{\text {fw }}(\mathrm{W})$ & 278.98 & 278.98 \\
$P_{\text {stator }} \mathrm{AC}(\mathrm{W})$ & - & 101.241 \\
$P_{\text {rotor }} \mathrm{AC}(\mathrm{W})$ & - & 66.489 \\
$P_{\text {core }}$ tot $(\mathrm{W})$ & 175.99 & 167.73 \\
\hline \hline
\end{tabular}

$P_{\text {stator }} \mathrm{AC}$ and $P_{\text {rotor }} \mathrm{AC}$ correspond to stator and rotor core losses in the induction machine respectively. The results of the classical no-load test and the DCM test for a value of the stator voltage $V_{\mathrm{AC}}$ equal to $220 \mathrm{~V}$ are given in Table IV. In this Table, "-" corresponds to unknown or nonexistent values and $I_{\mathrm{AC}}$ is the stator current of induction machine. Note that the presented values are global ones and so they do not account for the harmonics. Table IV clearely shows that the rotor core losses can not be neglected since they represent up to $39.6 \%$ of total core losses according to DCM test and $12 \%$ of total noload power. These values are compliant with those presented in [39]. Hence, replacing NO fully processed material by GO electrical steel in the rotor is relevant in order to reduce the core losses.

DC Machine

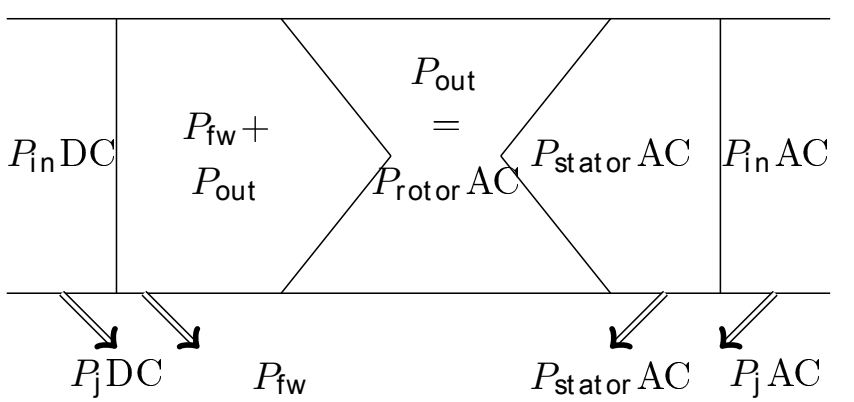

Fig. 15. Scheme of power balance for the DCM test

\section{CONCLUSION}

In this work, replacing $\mathrm{NO}$ material by $\mathrm{GO}$ material in a die casting copper rotor and a new shifting lamination method was investigated. This configuration allowed to decrease the stray load losses, the rotor and stator core losses as well as the stator winding losses. In fact, the good performance of the die casting copper rotor with GO sheets shifted at $90^{\circ}$ from each others is due to a compensation made by the good magnetic properties along the RD as well as the difference of insulation coating compared to NO material. The efficiency of an $11 \mathrm{~kW}$ induction machine was improved around 1.6 points without any dimension modification.
Of course, the whole manufacturing process of that kind of machine implies some additional costs compared to a conventional one due to the use of GO steel as well as the use of die casting copper process. Nevertheless, the purchase cost of an electrical machine is less than $3 \%$ of its cost of ownership [40]. Moreover, the cost of running is $70 \%$ to $95 \%$. Hence, the manufacturing process additional costs can easily be fully depreciated in the useful life of the machine.

\section{ACKNOWLEDGEMENT}

This work has been achieved within the framework of CE2I project (Convertisseur d'Énergie Intégré Intelligent) and FAVI. CE2I is co-financed by European Union with the financial support of European Regional Development Fund (ERDF), French State and the French Region of Hauts-de-France. FAVI is a French company specialized in copper alloy pressure die-casting. This program is also supported by ThyssenKrupp Electrical Steel which provided us the GO materials.

\section{REFERENCES}

[1] "IEC60034: Rotating electrical machines - Part 30-1: Efficiency classes of line operated AC motors (IE code)," International Electrotechnical Commission, Standard, 2015.

[2] A. Boglietti, A. Cavagnino, L. Ferraris, M. Lazzari, and G. Luparia, "No tooling cost process for induction motors energy efficiency improvements," IEEE Trans. Ind. Appl., vol. 41, no. 3, pp. 808-816, 2005.

[3] L. Alberti, N. Bianchi, A. Boglietti, and A. Cavagnino, "Core axial lengthening as effective solution to improve the induction motor efficiency classes," IEEE Trans. Ind. Appl., vol. 50, no. 1, pp. 218-225, 2014.

[4] E. B. Agamloh, A. Boglietti, and A. Cavagnino, "The incremental design efficiency improvement of commercially manufactured induction motors," IEEE Trans. Ind. Appl., vol. 49, no. 6, pp. 2496-2504, 2013.

[5] J. L. Kirtley, J. G. Cowie, E. F. Brush, D. T. Peters, and R. Kimmich, "Improving induction motor efficiency with die-cast copper rotor cages," IEEE Power Eng. Soc. Gen. Meet., pp. 1-6, 2007.

[6] E. Chiricozzi, F. Parasiliti, and M. Villani, "New materials and innovative technologies to improve the efficiency of three-phase induction motors. a case study," in XVIth Int. Conf. on Electric. Mach. (ICEM), 2004, pp. $5-8$.

[7] D. Ashwin, S. Ashok, M. Dixit, and V. Chavan, "Design optimization of $15 \mathrm{kw}, 2$-pole induction motor to achieve IE4 efficiency level with copper die casting," Int. Conf. Adv. Power Energy, pp. 98-102, 2015.

[8] F. Parasiliti and M. Villani, "Design of high efficiency induction motors with die-casting copper rotors," in Energy Efficiency in Motor Driven Systems, F. Parasiliti and P. Bertoldi, Eds. Berlin, Heidelberg: Springer Berlin Heidelberg, 2003, pp. 144-151.

[9] I. Khader, A. Renz, A. Kailer, and D. Haas, "Thermal and corrosion properties of silicon nitride for copper die casting components," J. of the European Ceramic Soc., vol. 33, no. 3, pp. 593 - 602, 2013.

[10] Solutions for your high efficiency industrial asynchronous motors. [Online]. Available: http://www.favi.com/en/copper-rotor-industry/

[11] Y. N. Feng, J. Apsley, S. Williamson, A. C. Smith, and D. M. Ionel, "Reduced losses in die-cast machines with insulated rotors," IEEE Trans. Ind. Appl., vol. 46, no. 3, pp. 928-936, 2010.

[12] N. Glew, "Stray load losses in induction motors: a challenge to academia," IEEE Power Eng. Rev., vol. 12, no. 1, pp. 27-32, 1998.

[13] S. Cicalé, L. Albini, F. Parasiliti, and M. Villani, "Design of a permanent magnet synchronous motor with grain oriented electrical steel for directdrive elevators," in XX th Int. Conf. on Electric. Mach. (ICEM), 2012.

[14] Y. Sugawara and K. Akatsu, "Characteristics of a switched reluctance motor using grain-oriented electric steel sheet," in ECCE Asia Downunder, 2013.

[15] J.-F. Brudny, B. Cassoret, R. Lemaître, and J.-N. Vincent, "Magnetic core and use of magnetic core for electrical machines," WO Patent Application WO 2009/030 779 A1, Mar. 12, 2009.

[16] - "Magnetic core and use of magnetic core for electrical machines," US Patent Application US 2011/0 260574 A1, Oct. 27, 2011. 
[17] S. Lopez, B. Cassoret, J. F. Brudny, L. Lefebvre, and J. N. Vincent, "Grain oriented steel assembly characterization for the development of high efficiency ac rotating electrical machines," IEEE Trans. Magn., vol. 45, no. 10, pp. 4161-4164, 2009.

[18] B. Cassoret, S. Lopez, J.-F. Brudny, and T. Belgrand, "Non-segmented grain oriented steel in induction machines," $\mathrm{Pr}$. Electromagn. Res C, vol. 47, pp. 1-10, 2014.

[19] R. Lemaître and T. Belgrand, "Matériaux magnétiques doux cristallins. acier électrique à grains orientés," Techniques de l'ingénieur, 2014.

[20] V. Mallard, G. Parent, C. Demian, J. F. Brudny, and A. Delamotte, "Increasing the energy-efficiency of induction machines by the use of grain oriented magnetic materials and die-casting copper squirrel cage in the rotor," in Int. Electr. Mach. and Drives Conf. (IEMDC), May 2017, pp. $1-6$.

[21] D. T. Peters, J. G. Cowie, and E. F. Brush, "Die casting copper motor rotors: Mold materials and processing for cost-effective manufacturing," in Energy Efficiency Improvements in Electronic Motors and Drives. Springer Berlin Heidelberg, 2000, pp. 39-51.

[22] D. T. Peters, J. G. Cowie, E. F. Brush, and S. P. Midson, "Die-cast copper motor rotors: Die materials and process considerations for economical copper rotor production," in Energy Efficiency in Motor Driven Systems. Springer Berlin Heidelberg, 2003, pp. 128-135.

[23] D. T. Peters, S. Midson, W. Walkington, E. Brush Jr, and J. Cowie, "Porosity control in copper rotor die castings," in Trans. of the North Amer. Die Casting Assoc. Congress, Indianapolis, IN, 2003.

[24] J. Cowie and D. Brender, "Die-cast copper rotors for improved motor performance," Annu. Pulp and Paper Indus. Techn. Conf., pp. 42-49, 2003.

[25] P. Baudouin, A. Belhadj, and Y. Houbaert, "Effect of the rapid heating on the magnetic properties of non-oriented electrical steels," J. Magn. Magn. Mater., vol. 238, no. 2-3, pp. $221-225,2002$.

[26] A. Belhadj, P. Baudouin, F. Breaban, A. Deffontaine, M. Dewulf, and Y. Houbaert, "Effect of laser cutting on microstructure and on magnetic properties of grain non-oriented electrical steels," J. Magn. Magn. Mater., vol. 256, no. 1, pp. 20 - 31, 2003.

[27] A. Belhadj, P. Baudouin, and Y. Houbaert, "Simulation of the haz and magnetic properties of laser cut non-oriented electrical steels," J. Magn. Magn. Mater, vol. 248, no. 1, pp. 34 - 44, 2002.

[28] X. Duan, H. Huneus, T. Kochmann, K. Leuridan, R. Kaczmarek, and F. Protat, "Effect of annealing temperature and heating rate on the magnetic and mechanical properties of electrical steel," J. Magn. Magn. Mater., vol. 160, pp. 133-135, jul 1996.

[29] C. Paris and O. Walti, "A new technology to make rotors with copper as magnetic conductor," in Energy Efficiency in Motor Driven Systems. Springer Berlin Heidelberg, 2003, pp. 152-161.

[30] H. Naumoski, B. Riedmüller, A. Minkow, and U. Herr, "Investigation of the influence of different cutting procedures on the global and local magnetic properties of non-oriented electrical steel," J. Magn. Magn. Mater, vol. 392, pp. 126-133, oct 2015.

[31] A. Stening, "Analysis and Reduction of Parasitic Effects in Induction Motors With Die-Cast Rotors," Ph.D. dissertation, School of Electrical Engineering, 2013.

[32] C. C. Silveira, M. A. Da Cunha, and V. T. L. Buono, "The influence of internal oxidation during decarburization of a grain oriented silicon steel on the morphology of the glass film formed at high temperature annealing,” J. Magn. Magn. Mater., vol. 358-359, pp. 65-69, 2014.

[33] "IEC60404: Magnetic alloys and steels - Part 2 - methods of measurement of the magnetic properties of electrical steel strip and sheet by means of an epstein frame," International Electrotechnical Commission, Standard, 2008

[34] G. Parent, R. Penin, J. P. Lecointe, J. F. Brudny, and T. Belgrand, "Analysis of the magnetic flux distribution in a new shifted nonsegmented grain oriented ac motor magnetic circuit," IEEE Trans. Magn., vol. 49, no. 5, pp. 1977-1980, 2013.

[35] G. H. Shirkoohi and M. A. M. Arikat, "Anisotropic properties of high permeability grain-oriented $3.25 \%$ si-fe electrical steel," IEEE Trans. Magn., vol. 30, no. 2, pp. 928-930, 1994.

[36] "IEC60034 - rotating electrical machines - Part 2-1: Standard methods for determining losses and efficiency from tests (excluding machines for traction vehicles)," International Electrotechnical Commission, Standard, 2014.

[37] A. Nakahara, S. Kikuchi, K. Nishihama, T. Miyoshi, and K. Kaihatsu, "High-frequency interbar current losses in cage induction motors under no-load condition," IEEE Trans. Energy Convers., vol. 29, no. 3, pp. 698-705, 2014.

[38] A. Boglietti, A. Cavagnino, M. Lazzari, and M. Pastorelli, "International standards for the induction motor efficiency evaluation: a critical analysis of the stray-load loss determination," IEEE Trans. Ind. Appl., vol. 40, no. 5, pp. 1294-1301, 2004.

[39] J.-F. Brudny and R. Romary, "Analysis of the slotting effect on the induction machine dynamic iron losses," Comp. Fields Models of Electromagn. Devices, vol. 34, pp. 27-73, 2010.

[40] Cost of ownership. [Online]. Available: http://new.abb.com/motors-generators/cost-of-ownership 